\title{
Cognitive-behavioral therapy in pregnant women with generalized anxiety disorder: a retrospective cohort study on therapeutic efficacy, gestational age and birth weight
}

\author{
Faruk Uguz, (iD) Mehmet Ak \\ Department of Psychiatry, University of Necmettin Erbakan, Meram Faculty of Medicine, Konya, Turkey.
}

\begin{abstract}
Objective: To evaluate the efficacy of cognitive behavioral therapy in the treatment of generalized anxiety disorder during pregnancy and its effects on gestational age and birth weight.

Methods: The sample included 28 untreated patients and 23 patients treated with CBT. Psychiatric diagnoses were determined through the Structured Clinical Interview for the DSM-IV. Symptom severity was assessed with standardized rating scales.

Results: Post-treatment levels of anxiety symptoms were significantly lower than baseline. There was no significant difference in gestational age or newborn birth weight between the cognitive behavioral therapy group and the untreated group.

Conclusions: Cognitive behavioral therapy appears to be a safe and effective treatment for generalized anxiety disorder during pregnancy.
\end{abstract}

Keywords: Pregnancy; anxiety disorder; psychotherapy

\section{Introduction}

Pregnancy, one of the most important life events, includes striking biological, psychological and social changes. The onset or exacerbation of psychiatric disorders may occur in some women during this period. ${ }^{1-3}$ Studies have suggested that approximately $20 \%$ of pregnant women have at least one psychiatric disorder, most frequently depressive and anxiety disorders. ${ }^{4-6}$

Generalized anxiety disorder (GAD) appears to be the most common anxiety disorder during pregnancy, with a prevalence rate of up to $10.5 \% .^{3}$ It has recently been suggested that the prevalence rate of GAD is significantly higher in pregnant women than non-pregnant women. ${ }^{4}$ Meta-analyses have shown that maternal anxiety during pregnancy is associated with increased risk of preterm birth and lower birth weight. ${ }^{7,8}$ Specifically, GAD may negatively affect the intrauterine growth of the fetus. ${ }^{9}$ In addition, it has also been reported that newborns of women with GAD had significantly lower blood levels of brain-derived neurotrophic factor than newborns of healthy women. ${ }^{10}$

Pharmacotherapy, especially antidepressants, and cognitive-behavioral therapy (CBT) are the main treatment options for anxiety disorders. Selective serotonin reuptake inhibitors are frequently used to treat depression and anxiety disorders. Although these antidepressants appear to be safe in pregnant women, the literature reports some concerns about their usage during pregnancy.

Correspondence: Faruk Uguz, Necmettin Erbakan Üniversitesi Meram Tıp Fakültesi, Psikiyatri Anabilim Dali Akyokuş, 42080, Konya, Turkey.

E-mail: farukuguz@gmail.com

Submitted Nov 19 2019, accepted Mar 12 2020, Epub Aug 032020.
Although most patients with severe symptoms require pharmacological agents (with or without psychotherapy), CBT can be just as effective as pharmacotherapy for most anxiety disorders and is recommended as the first-line treatment in patients with mild anxiety. ${ }^{11}$ It has been well documented that CBT significantly reduces GAD symptoms in the general population. ${ }^{11,12}$ Therefore, as an alternative treatment in pregnant women, CBT can circumvent the risks of antidepressants on neonatal outcome. In addition, it has been reported that pregnant women show more willingness for and have fewer concerns about psychoterapy than pharmacotherapy. ${ }^{13}$ However, evidence about the efficacy of CBT for psychiatric disorders during pregnancy is very limited and is predominantly based on major depression trials with small sample sizes. ${ }^{14}$ Moreover, the safety and possible adverse effects of cognitive-behavioral psychotherapy on neonatal outcomes is currently unknown. In the present study, we aimed to assess the effects of CBT on anxiety symptoms, gestational age, and birth weight in the infants of pregnant women with GAD.

\section{Methods}

This retrospective study reviewed the clinical records of pregnant women admitted to the Perinatal Psychiatry Outpatient Clinic of a university hospital in Konya, Turkey. The clinic provides counselling and treatment with CBT

How to cite this article: Uguz F, Ak M. Cognitive-behavioral therapy in pregnant women with generalized anxiety disorder: a retrospective cohort study on therapeutic efficacy, gestational age and birth weight. Braz J Psychiatry. 2021;43:61-64. http://dx.doi.org/ 10.1590/1516-4446-2019-0792 
or pharmacological agents. The patients were referred by psychiatrists from the same university hospital and psychiatrists from state hospitals in the same city for psychiatric treatment and follow-up during pregnancy and the postpartum period. A total of 51 women (23 in the CBT group and 28 in the untreated group) were included. The inclusion criteria were: 1) a minimun of 18 years of age; 2) at least 8 weeks of follow-up with individual CBT; 3) first examination before the 27th gestational week; 4) a diagnosis of GAD; 5) no prior CBT. The exclusion were: 1) mental retardation; 2) any fetal malformation; 3) a history schizophrenia or related psychotic disorders; 4) alcohol or substance use during pregnancy; 5) smoking during pregnancy; 6) comorbid mood or anxiety disorders; 7) a history of medical illnesses (e.g., endocrine abnormalities, cardiovascular and pulmonary system diseases, neurological diseases, and metabolic diseases) or pregnancy-related complications (e.g., gestational hypertension, imminent abortion, placenta previa and other placental abnormalities, vaginal bleeding, and gestational diabetes); 8) any maternal infection that could negatively affect fetal growth; 9) treatment with psychotropic drugs or psychotherapy other than CBT during pregnancy. The untreated group included pregnant patients with GAD who did not accept treatment at the first interview and did not apply to the psychiatry outpatient clinic for a follow-up psychiatric evaluation during pregnancy.

Data on sciodemographic and obstetric characteristics were collected during the first evaluation. It was ensured that the study did not interfere with patient treatment. The follow-up assessments and CBT sessions were performed by psychiatrists. The CBT sessions included psychoeducation, relaxation exercises and intervention for cognitive distortions. The Structured Clinical Interview for DSM-IV (SCID-I) was used to screen for psychiatric disorders. ${ }^{15}$ The levels of anxiety symptoms and the efficacy of CBT were assessed with the Hamilton Rating Scale for Anxiety (HAM-A) ${ }^{16}$ Gestational age at delivery was calculated according to the date of last menstruation. Birth weight was obtained from hospital records and the mother's report. Treatment response was defined as a reduction of least $50 \%$ in baseline HAM-A scores.

The data were analyzed using SPSS version 16.0. The chi-square test and Fisher's exact test were used to compare categorical variables between the groups. Preand post-treatment HAM-A scores were compared with a paired-samples $t$-test. Gestational age and birth weight between treated and untreated groups were compared with a $t$-test or the Mann-Whitney $U$ test for independent groups.

\section{Ethics statement}

The study's procedures were approved by the hospital's ethics committee.

\section{Results}

The mean age of the participants $(n=51)$ was $31.80 \pm 4.34$ years. All women were married and most were unemployed $(\mathrm{n}=44,86.3 \%)$ and multigravida $(\mathrm{n}=42,82.4 \%)$. Ten participants $(19.6 \%)$ had completed university. The mean number of children was $1.676 \pm 0.94$. Sixteen (31.4\%) women had a history of abortion and 28 (55.9\%) infants were female. In the CBT group, the mean gestational age at the first and last evaluation was $13.26 \pm 6.61$ weeks (range $=5-26$ ) and 33.04 \pm 1.89 weeks (range $=30-36$ ), respectively. The mean follow-up period was $19.78 \pm 5.52$ (range $=10-29$ ) weeks, and the mean number of CBT sessions was $7.04 \pm 0.87$ (range $=6-9$ ).

In the CBT group, the mean HAM-A scores reduced significantly between baseline and the 8th week of treatment: from $6.96 \pm 2.75$ to $15.12 \pm 6.03$. The HAM-A score decreased by at least $50 \%$ in $14(60.9 \%)$ patients treated with CBT. As shown in Table 1, there was no significant difference in age, educational level, employment status, economic level, history of abortion, infant gender, number of children, proportion of primiparity, gestational week or HAM-A score at the first evaluation between the untreated and treated groups. Although the mean birth weight of the infants was $150 \mathrm{~g}$ lower in the untreated group than the CBT group, this was not a significant difference $(p=0.134)$. Additionally, the gestational age of the newborns did not differ significantly between two groups $(p=0.443)$.

\section{Discussion}

To the best of our knowledge, no published studies have examined the clinical efficacy of CBT in pregnant women with GAD, a psychiatric disorder frequently observed in this population. Moreover, this is the first study to compare the gestational age and birth weight of newborns in untreated and CBT-treated patient groups. Indeed, pharmacotherapy may be a new source of worry for pregnant women due to potential adverse effects on the fetus. It has been suggested that more pregnant than nonpregnant women prefer psychotherapy alone. ${ }^{13}$

The safety and efficacy of psychotherapy during pregnancy are important questions that should be addressed. It has already been well documented that CBT is efficacious for treating anxiety disorders in the general population. A recent meta-analysis found that CBT is a moderately efficacious treatment for GAD compared to placebo. ${ }^{17}$ Although it is generally assumed that a psychiatric treatment known to be effective in non-perinatal women will also be effective during pregnancy, this assumption should be confirmed by actual studies. Austin et al. ${ }^{18}$ reported that a prenatal CBT group intervention in pregnant women with mild to moderate depressive or anxiety symptoms may reduce the risk of postnatal anxiety disorders. Similarly, Green et al. ${ }^{19}$ reported that cognitive-behavioral group therapy had beneficial effects on prenatal anxiety. In contrast, Bittner et al. ${ }^{20}$ found that the same treatment method had no significant effect on pregnant women with elevated levels of anxiety or depression. On the other hand, a meta-analysis suggested that for depression, medication plus CBT or medication alone had a greater effect than other types of psychotherapy alone during the perinatal period. ${ }^{21}$ In our sample, GAD symptom severity was significantly reduced with $\mathrm{CBT}$, and more than 
Table 1 Sociodemographic and obstetrical characteristics of the study groups

\begin{tabular}{|c|c|c|c|}
\hline & Untreated group $(n=28)$ & CBT group $(n=23)$ & $p$-value \\
\hline Age (years) & $31.32 \pm 3.89$ & $32.39 \pm 4.76$ & $0.714 *$ \\
\hline $\begin{array}{l}\text { Education } \\
\text { Primary school } \\
\text { Secondary school } \\
\text { University }\end{array}$ & $\begin{array}{c}18(64.3) \\
5(17.9) \\
5(17.9)\end{array}$ & $\begin{array}{l}12(52.2) \\
6(26.1) \\
5(21.7)\end{array}$ & $0.667^{\dagger}$ \\
\hline $\begin{array}{l}\text { Employment status } \\
\text { Unemployed }\end{array}$ & $24(85.7)$ & $20(87.0)$ & 1.000 \\
\hline $\begin{array}{l}\text { Economic level } \\
\text { Low } \\
\text { Moderate } \\
\text { High }\end{array}$ & $\begin{array}{c}3(10.7) \\
22(78.6) \\
3(10.7)\end{array}$ & $\begin{array}{c}1(4.3) \\
19(82.6) \\
3(13.0)\end{array}$ & $0.692^{\dagger}$ \\
\hline $\begin{array}{l}\text { Primiparity } \\
\text { History of abortion }\end{array}$ & $\begin{array}{l}5(17.9) \\
8(28.6)\end{array}$ & $\begin{array}{l}4(17.4) \\
8(34.8)\end{array}$ & 0.764 \\
\hline $\begin{array}{l}\text { Gender of baby } \\
\text { Female }\end{array}$ & $16(57.1)$ & $12(42.9)$ & $0.782^{\ddagger}$ \\
\hline $\begin{array}{l}\text { Number of children } \\
\text { Gestational age at the first evaluation (weeks) } \\
\text { HAM-A score at the first evaluation } \\
\text { Gestational age at birth (weeks) } \\
\text { Birth weight (g) }\end{array}$ & $\begin{array}{c}1.75 \pm 0.97 \\
14.64 \pm 4.79 \\
14.28 \pm 4.06 \\
38.14 \pm 1.30 \\
3,090 \pm 357\end{array}$ & $\begin{array}{c}1.56 \pm 0.89 \\
13.26 \pm 6.61 \\
15.12 \pm 6.03 \\
38.39 \pm 1.16 \\
3,241 \pm 342\end{array}$ & $\begin{array}{l}0.486^{\S} \\
0.392^{*} \\
0.617^{*} \\
0.443^{\S} \\
0.134^{*}\end{array}$ \\
\hline
\end{tabular}

Data presented as $\mathrm{n}(\%)$ or mean \pm standard deviation.

$\mathrm{CBT}=$ cognitive-behavioral therapy; HAM-A = Hamilton Rating Scale for Anxiety.

${ }^{*} t$-test; ${ }^{\dagger} \chi^{2}$ test; ${ }^{\ddagger}$ Fisher's exact test; ${ }^{\S}$ Mann-Whitney $U$ test.

half of the patients responded to CBT. These results suggest that CBT may effectively alleviate anxiety symptoms in pregnant women with GAD. Our results also suggest that CBT does not appear to be detrimental to the gestational age or birth weight of the infant. If these results are confirmed by further studies, CBT can be considered an alternative treatment to pharmacotherapy in patients with GAD who do not have comorbid disorders, such as major depression or other anxiety disorders.

Diagnosis with a structured clinical interview, assessment with standardized symptom rating scales, and comparison between untreated patients and patients with CBT are the main strengths of this study. However, its small sample size, retrospective design and lack of a placebo-controlled group are its main limitations. In addition, this study did not examine the onset time or duration of anxiety. A history of prior anxiety and its duration could affect treatment response. Nevertheless, despite these limitations, the results of this study indicate that CBT may be beneficial in the treatment of GAD during pregnancy and has no adverse effects on the gestational age or birth weight of the infant. Further controlled studies with larger sample sizes are needed to confirm these results.

\section{Acknowledgements}

This research received neither funding nor support from any commercial or non-commercial organization, and the authors have no conflicts of interest in connection with submitted paper.

\section{Disclosure}

The authors report no conflicts of interest.

\section{References}

1 Altshuler LL, Hendrick V, Cohen LS. Course of mood and anxiety disorders during pregnancy and postpartum period. J Clin Psychiatry. 1998;59 Suppl 2:29-33.

2 Guler O, Sahin FK, Emul HM, Ozbulut O, Gecici O, Uguz F, et al. The prevalence of panic disorder in pregnant women during the third trimester of pregnancy. Compr Psychiatry. 2008;49:154-8.

3 Goodman JH, Chenausky KL, Freeman MP. Anxiety disorders during pregnancy: a systematic review. J Clin Psychiatry. 2014;75:e1153-84.

4 Uguz F, Yakut E, Aydogan S, Bayman MG, Gezginc K. Prevalence of mood and anxiety disorders during pregnancy: a case-control study with a large sample size. Psychiatry Res. 2019;272:316-8.

5 Felice E, Saliba J, Grech V, Cox J, Calleja N. Antenatal psychiatric morbidity in Maltase women. Gen Hosp Psychiatry. 2007;29:501-5.

6 Borri C, Mauri M, Oppo A, Banti S, Rambelli C, Ramacciotti D, et al. Axis I psychopathology and functional impairment at the third month of pregnancy: results from the perinatal depression-research and screening unit (PND-ReScU) study. J Clin Psychiatry. 2008;69: 1617-24.

7 Ding XX, Wu YL, Xu SJ, Zhu RP, Jia XM, Zhang SF, et al. Maternal anxiety during pregnancy and adverse birth outcomes: a systematic review and meta-analysis of prospective cohort studies. J Affect Disord. 2014;159:103-10.

8 Grigoriadis S, Graves L, Peer M, Mamisashvili L, Tomlinson G, Vigod $\mathrm{SN}$, et al. Maternal anxiety during pregnancy and the association with adverse perinatal outcomes: systematic review and meta-analysis. J Clin Psychiatry. 2018;79:17r12011.

9 Uguz F, Gezginc K, Yazici F. Are major depression and generalized anziety disorder associated with intrauterine growth restriction in pregnant women? A case-control study. Gen Hosp Psychiatry. 2011; 33:640.e7-9. 
10 Uguz F, Sonmez EO, Sahingoz M, Gokmen Z, Basaran M, Gezginc K, et al. Maternal generalized anxiety disorder during pregnancy and fetal brain development: a comparative study on cord blood brain-derived neurotrophic factor levels. J Psychosom Res. 2013;75:346-50.

11 Katzman MA, Bleau P, Blier P, Chokka P, Kjernisted K, Van Ameringen $\mathrm{M}$, et al. Canadian clinical practice guidelines for the management of anxiety, posttraumatic stres and obsessive-compulsive disorders. BMC Psychiatry. 2014;14 Suppl 1:S1.

12 Andrews G, Bell C, Boyce P, Gale C, Lampe L, Marwat O, et al. Royal Australian and New Zealand College of Psychiatrists clinical practice guidelines for the treatment of panic disorder, social anxiety disorder and generalized anxiety disorder. Aust N Z J Psychiatry. 2018;52:1109-72.

13 Arch JJ. Cognitive behavioral therapy and pharmacotherapy for anxiety: treatment prefrences and credibility among pregnant and non-pregnant women. Behav Res Ther. 2014;52:53-60.

14 van Ravesteyn LM, Lambregtse-van den Berg MP, Hoogendijk WJ, Kamperman AM. Interventions to treat mental disorders during pregnancy: a systematic review and multiple treatment meta-analysis. PLoS One. 2017;12:e0173397.

15 First MB, Spitzer RL, Gibbon M, Williams JB. Structured Clinical Interview for DSM-IV Clinical Version (SCID-I/CV). Washington: American Psychiatric Press; 1997.
16 Hamilton $\mathrm{M}$. The assessment of anxiety states by rating. $\mathrm{Br} \mathrm{J}$ Med Psychol. 1959;32:50-5.

17 Carpenter JK, Andrews LA, Witcraft SM, Powers MB, Smits JA, Hofmann SG. Cognitive behavioral therapy for anxity and related disorders: a meta-analysis of randomized placebo-controlled trials. Depress Anxiety. 2018;35:502-14.

18 Austin MP, Frilingos M, Lumley J, Hadzi-Pavlovic D, Roncolato W, Acland $\mathrm{S}$, et al. Brief antenala cognitive-behaviour therapy group intervention for the prevention of postnatal depression and anxiety: a randomised controlled trial. J Affect Disord. 2008;105: 35-44.

19 Green SM, Haber E, Frey BN, McCabe RE. Cognitive-behavioral group treatment for perinatal anxiety: a pilot study. Arch Womens Ment Health. 2015;18:631-8.

20 Bittner A, Peukert J, Zimmermann C, Junge-Hoffmeister J, Parker LS, Stöbel-Richter Y, et al. Early Intervention in pregnant women with elevated anxiety and depressive symptoms: efficacy of a cognitivebehavioral group program. J Perinat Neonat Nurs. 2014;28: 185-95.

21 Bledsoe SE, Grote NK. Treating depression during pregnancy and the postpartum: a preliminary meta-analysis. Res Soc Work Pract. 2006;16:109-20. 